\title{
Effect of Slow Diaphragmatic Breathing Technique on Heart Rate, Blood Pressure and Peripheral Oxygen Saturation in Hypertensive Elderly
}

\author{
David Paulo Ramalheira Catela ${ }^{1 *}$ and Cristiana Isabel André Mercê ${ }^{2}$ \\ ${ }^{1}$ Quality of Life Research Centre (CIEQV) and Research Centre of the Polytechnique Institute of Santarém (UIIPS), Portugal \\ ${ }^{2}$ Interdisciplinary Centre for the Study of Human Performance (CIPER), Portugal
}

\begin{abstract}
Slow breathing can be used as a complement for hypertension treatment. The aim of the study was to verify the effect of a breathing technique on cardiac autonomic function in elderly ( $\mathrm{N}=22,76.36 \pm 7.93$ years old, 13 women); thirteen had optimal to Normal High Blood Pressure (ONH group) and nine had Mild to Moderate Isolated Systolic Pressure (MMS group). In both groups, vital signs were collected in two breathing conditions: i) Baseline (B)- participants breath at their normal pace; ii) Diaphragmatic (D)participants breath at a slow pace, predominantly abdominal. Considering all participants, results revealed that during D condition Respiratory Frequency (RF) and Heart Rate Frequency (HR) were significantly reduced, and Peripheral Oxygen Saturation (SpO ${ }_{2}$, High Frequency (HF) and Heart Rate Variability Index (HRVi) significantly augmented, a significant reduction of. In D condition, both groups significantly augmented $\mathrm{SpO}_{2}$. Additionally, in B condition, MMS group had significantly less $\mathrm{SpO}_{2}$ than $\mathrm{ONH}_{\text {group}}$; but, in D condition no significant difference was found between groups. Similarly, in B condition, MMS group had significantly higher Diastolic Pressure (DP), but in D condition no significant difference was found between groups. Also, compared to B condition, in D condition MMS group significantly reduced Systolic Pressure (SP), DP and Pulse (P- the difference between SP and DP). Consequently, during the D breathing, MMS subjects benefited of better blood pressure and peripheral oxygenation conditions, with probable enhancement of Heart Rate Variability (HRV). Results of this study support the hypothesis that an easily learned diaphragmatic breathing technique, inexpensive and non-intrusive, can help elderly with isolated systolic hypertension, to remediate its effects on vital signs, as a non-clinical complementary treatment.
\end{abstract}

KEYWORDS: Breathing technique; Elderly; Blood pressure; Peripheral oxygen saturation

\section{INTRODUCTION}

A slower respiration usually involves the use of the diaphragm, probably without increase of respiratory workload. Slow breathing increases baroreflex sensitivity [1-32,14-22], which is lower in essential hypertensive than in normotensive subjects $[28,29]$.
Because the baroreflex modulates cardiac vagal and sympathetic outflow to the sinus node in the heart [33-36], slowing breathing frequency results in a reduction of Heart Rate (HR) [37] and reduces muscle nerve sympathetic activity [2-16]. That's why it has been suggested that reducing breathing frequency can be used
Quick Response Code:

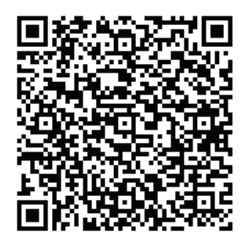

Address for correspondence: David Catela, Motricity Sciences PhD, Child Motor Development MSc, Life Quality Research Centre (CIEQV) and Research Unity of the Polytechnic Institute of Santarém (UIIPS), Complexo Andaluz, Portugal

Received: October 16, $2020 \quad$ Published: January 04, 2021

How to cite this article: David Paulo Ramalheira C, Cristiana Isabel André M. Effect of Slow Diaphragmatic Breathing Technique on Heart Rate, Blood Pressure and Peripheral Oxygen Saturation in Hypertensive Elderly. 2020 - 3(1) OAJBS.ID.000245. DOI: 10.38125/OAJBS.000245 
as a complement for hypertension treatment [26,38]. Probably, an increase of Oxygen Saturation $\left(\mathrm{SpO}_{2}\right)$ may also occur, as in patients with chronic heart failure, regardless of the amount of ventilation [27] and particularly for cases with lower $\mathrm{SpO}_{2}$ values [4].

Heart Rate Variability (HRV) represents the variations of the RR intervals, i.e., the time elapsing between two consecutive $\mathrm{R}$ waves and has been used as an expression of physiological factors that modulate the heart rhythm [6] .The Sympathetic Nervous System (SNS) acts to increase heart rate and the Parasympathetic Nervous System (PNS) acts to lower heart rate [35] . Hypertension results in a decrease in HRV, and an increase in sympathetic activity, detected by a greater low frequency power (LF) and a smaller high frequency power (HF) at supine rest; evolving with passive tilting to some increase and decrease, respectively; meaning a cardiac sympathetic tone increase and a cardiac vagal tone and modulation decrease [17], with negative consequences on blood pressure, particularly in severe hypertension [25].

Therefore, the purpose of the present study was to verify the effect of a diaphragmatic breathing technique on cardiac autonomic function in hypertensive elderly, by analysis of $\mathrm{HR}, \mathrm{BP}, \mathrm{SpO}_{2}$, and short-term HRV parameters.

\section{METHODS}

\section{Sample}

The sample was composed of 22 elderlies (76.05 \pm 7.98 years of age), 13 women, 13 with optimal to normal high blood pressure (prehypertension), and 9 with mild to moderate systolic isolated pressure [8-24]. Based on clinical history, ambulatory and successive experimental blood pressure registrations, no signs of white coat effect or masked hypertension were detected. One participant was taking medication for depression, and four with mild isolated systolic hypertension had diabetes. There was no report of damage of kidney, heart or brain [21-24]; [8-19]. Respiratory diseases (e.g., asthma, flu) were criteria of exclusion. Informed consent was obtained.

\section{Procedures and Data Treatment}

Respiratory Cycles per Minute (RF) were recorded through direct observation of thoracic and/or abdominal movements. Interval RR was carried out through Polar V800 [15] Pic Classic Check sphygmomanometer was used to collect Systolic (SBP) and
Diastolic (DBP) blood pressure every minute; and, Comed Eco Oximeter was used to collect Peripheral Oxygen Concentration $\left(\mathrm{SpO}_{2}\right)$, every 15 seconds. Records were conducted at the participants' places, with subjects in the supine position, in a quiet environment, with room temperature between 19 and $22{ }^{\circ} \mathrm{C}$. Participants were instructed to not smoke, drink alcohol or coffee 4h before data collection [21-23].

The experimental session was structured according to the following sequence: $6 \mathrm{~min}$ of rest with normal breathing, taken as Baseline (B), and 6mn Diaphragmatic Breathing Technique (D). In a previous training session, of about $20 \mathrm{mn}$, participants were instructed about and practiced the D, as follows: (1) put one hand on your chest and the other on your belly, (2) breath only through your nose, (3) fill your belly with air, and then let it go out slowly. No pace of breathing was imposed and no control the depth of breathing was made, so that each person could maintain comfortable breathing pace $[4,11,38]$. The recording of $B$ was always done first.

For HRV analysis gHRV software was used [33]. HR data were automatically filtered, employing adaptive thresholds in order to reject incorrect beats [34], whose values exceeded the cumulative mean threshold, and to eliminate points outside acceptable physiological values. A linear interpolation method, with filtered non-equispaced HR signal, was used to obtain frequency domain analysis [39]. For the spectral analysis a $4 \mathrm{~Hz}$ signal interpolation was used: with a window size of 120 s and a time shift of 60 s.

Data were statistically treated with the program IBM-SPSS, version 24. Shapiro-Wilk test was used to verify data normal distribution. Wilcoxon test (W) was used for within group comparison, with Monte Carlo test. Effect size (r) and Wilcoxon rank-biserial correlation coefficient (rrb) were calculated. MannWhitney $\mathrm{U}$ test $(\mathrm{Z})$ was used for between group comparison, with Monte Carlo test. Effect size (r) and Mann-Whitney Glass rankbiserial correlation (rrb) were calculated [12]. Spearman's Rank Order Correlation ( $\mathrm{rs}$ ) was used for determining association among variables.

\section{RESULTS}

Overall, during $\mathrm{D}$, and compared to $\mathrm{B}$, participants significantly reduced $\mathrm{RF}, \mathrm{HR}, \mathrm{SP}, \mathrm{DP}$ and $\mathrm{P}$, and significantly augmented $\mathrm{SpO}_{2}$ (Table 1).

Table 1: Descriptive statistics (Mean \pm Standard Deviation, Median), Wilcoxon test (W), effect size (r), and Wilcoxon rankbiserial correlation coefficient (rrb), of collected vital signs (below) for the sample ( $N=22$ ), in baseline (B) and diaphragmatic breathing (D) conditions.

\begin{tabular}{|c|c|c|c|c|c|c|c|}
\hline Vital Sign & B & D & GL & W & p & r & rrb \\
\hline $\mathrm{RF}$ & $18.95 \pm 3.46,19$ & $13.38 \pm 3.23,12$ & 132 & 9.582 & 0.0001 & 0.83 & 0.98 \\
\hline $\mathrm{HR}$ & $72.25 \pm 9.42,71$ & $70.73 \pm 9.64,71$ & 6632 & 21.513 & 0.0001 & 0.26 & 0.25 \\
\hline $\mathrm{SpO}_{2}$ & $94.27 \pm 2.42,95$ & $95.84 \pm 2.08,96$ & 528 & 13.332 & 0.0001 & 0.58 & 0.56 \\
\hline $\mathrm{SP}$ & $136.43 \pm 22.22,136$ & $123.57 \pm 18.04,124$ & 132 & 6.14 & 0.0001 & 0.53 & 0.46 \\
\hline $\mathrm{DP}$ & $72.86 \pm 8.32,72$ & $68.81 \pm 8.13,68$ & 132 & 5.215 & 0.0001 & 0.45 & 0.39 \\
\hline $\mathrm{P}$ & $63.58 \pm 18.34,65$ & $57.76 \pm 16.28,57$ & 132 & 5.033 & 0.0001 & 0.44 & 0.39 \\
\hline
\end{tabular}

RF: Respiratory Frequency; HR: Heart Rate Frequency; $\mathrm{SpO}_{2}$ : Peripheral Oxygen Saturation; SP: Systolic Pressure; DP: Diastolic Pressure; P: Pulse. 
If we compare the participants by their blood pressure status, both groups maintain significantly less RF, HR, SP, P, and significantly more $\mathrm{SpO}_{2}$, in D condition than in B condition. Additionally, MMS group significantly reduced DP (Table 2). Between groups, no significant differences were found in $\mathrm{RF}$, in $\mathrm{B}$ condition $\mathrm{Z}(132)=$ $.489, \mathrm{~ns}, \mathrm{r}=.04, \mathrm{rrb}=.09)$ and in $\mathrm{D}$ condition $(\mathrm{Z}(132)=.797, \mathrm{~ns}, \mathrm{r}=$ $.07, \mathrm{rrb}=.05)$, and a very lowly correlated and powered significant difference for HR in B condition $(\mathrm{Z}(6847)=5.745, p<.0001, \mathrm{r}=.06$, $\mathrm{rrb}=.09)$ and in $\mathrm{D}$ condition $(\mathrm{Z}(6847)=5.856, p<.0001, \mathrm{r}=.07$, $\mathrm{rrb}=.09)$. However, for $\mathrm{SpO}_{2}$, in $\mathrm{B}$ condition, ONH group revealed significantly higher values than MMS (Z (528) $=6.645, p<.0001, \mathrm{r}=$
.29 , rrb = .34); however, that difference disappeared in D condition $(\mathrm{Z}(528)=1.468, \mathrm{~ns}, \mathrm{r}=.06, \mathrm{rrb}=.07)$. For SP, ONH group preserved significantly better values in $\mathrm{B}$ and $\mathrm{D}$ conditions $(\mathrm{Z}(132)=9.569, p<$ $.0001, \mathrm{r}=0.83, \mathrm{rrb}=.98 ; \mathrm{Z}(132)=6.149, p<.0001, \mathrm{r}=.54, \mathrm{rrb}=.63$, respectively), and in $\mathrm{P}(\mathrm{Z}(132)=8.638, p<.0001, \mathrm{r}=.75, \mathrm{rrb}=.89$; $\mathrm{Z}(132)=6.150, p<.0001, \mathrm{r}=.54, \mathrm{rrb}=.63$, respectively); but in $\mathrm{DP}$, MMS group evolved from significant higher value in $\mathrm{B}$ condition to non-significant difference in D condition $(\mathrm{Z}(132)=6.255, p<.0001$, $\mathrm{r}=.54, \mathrm{rrb}=.64 ; \mathrm{Z}(132)=.646, \mathrm{~ns}, \mathrm{r}=.06, \mathrm{rrb}=.07$, respectively); (Table 2).

Table 2: Descriptive statistics (Mean \pm Standard Deviation, Median), Wilcoxon test (W), effect size (r), and Wilcoxon rankbiserial correlation coefficient ( $\mathrm{rrb}$ ), of collected vital signs (below) for the sample (N=13), in baseline (B) and diaphragmatic breathing (D) conditions.

\begin{tabular}{|c|c|c|c|c|c|c|c|c|}
\hline Vital Sign & Group & B & D & n & Z & p & r & rrb \\
\hline $\mathrm{RF}$ & ONH & $18.77 \pm 3.79,19$ & $13.62 \pm 3.20,13$ & 78 & 7.492 & 0.0001 & 0.85 & 1 \\
\hline & MMS & $19.22 \pm 2.93,19$ & $13.04 \pm 3.26,12$ & 54 & 6.016 & 0.0001 & 0.82 & 0.96 \\
\hline $\mathrm{HR}$ & $\mathrm{ONH}$ & $72.56 \pm 8.77,72$ & $71.20 \pm 8.11,71$ & 4338 & 17.848 & 0.0001 & 0.27 & 0.27 \\
\hline & MMS & $71.68 \pm 10.50,69$ & $69.87 \pm 11.94,71$ & 2324 & 12.126 & 0.0001 & 0.25 & 0.22 \\
\hline $\mathrm{SpO}_{2}$ & ONH & $94.90 \pm 1.90,95$ & $96.05 \pm 1.76,96$ & 312 & 10.036 & 0.0001 & 0.57 & 0.55 \\
\hline & MMS & $93.35 \pm 2.78,94$ & $95.54 \pm 2.44,96$ & 216 & 8,951 & 0.0001 & 0.61 & 0.57 \\
\hline SP & ONH & $122.01 \pm 12.98,124$ & $118.54 \pm 10.53,120$ & 78 & 2.949 & 0.01 & 0.34 & 0.28 \\
\hline & MMS & $157.26 \pm 15.11,154,5$ & $138.17 \pm 20.28,134$ & 54 & 5,400 & 0.0001 & 0.73 & 0.7 \\
\hline DP & ONH & $69.00 \pm 6.20,69$ & $68.81 \pm 8.13,68$ & 78 & 1.294 & ns & 0.15 & 0.13 \\
\hline & MMS & $78.43 \pm 7.86,76$ & $69.57 \pm 9.22,70$ & 54 & 5,377 & 0.0001 & 0.73 & 0.74 \\
\hline P & ONH & $53.01 \pm 14.22,58,5$ & $50.26 \pm 11.44,53,5$ & 78 & 2.769 & 0.01 & 0.31 & 0.31 \\
\hline & MMS & $78.83 \pm 11.69,76$ & $68.59 \pm 16.20,64,5$ & 54 & 4,313 & 0.0001 & 0.59 & 0.5 \\
\hline
\end{tabular}

RF: Respiratory Frequency; HR: Heart Rate Frequency; $\mathrm{SpO}_{2}$ : Peripheral Oxygen Saturation; SP: Systolic Pressure; DP: Diastolic Pressure; P: pulse by blood pressure status (Mild to Moderate Isolated Systolic Pressure- MMS, $n=9$; and, Optimal to Normal High blood pressure subjects- $\mathrm{ONH}, \mathrm{n}=13$ ).

Considering all participants, in the B condition, RF isn't associated with $\mathrm{SpO}_{2}(\mathrm{rs}(132)=-.051, \mathrm{~ns})$, however, in the $\mathrm{D}$ condition a significantly inverse association is observed $\operatorname{rs}(132)$ $=-.342, p<.0001$ ), meaning that when longer and predominantly diaphragmatic breathing was requested, less breathing cycles per minute became associated with greater peripheral oxygen saturation and vice-versa. However, when we split participants by blood pressure status, additional information is available; $\mathrm{ONH}$ group revealed significant inverse association in $\mathrm{B}$ and $\mathrm{D}$ conditions $(\mathrm{rs}(78)=-.302, \mathrm{p}<.01 ; \mathrm{rs}(78)=-.301, p<.01$, respectively $)$; whereas MMS group revealed a divergent pattern, in $B$ condition a significant direct association is present $(\operatorname{rs}(54)=.390, p<.01)$, meaning that greater breathing frequency is associated with greater peripheral oxygen saturation, whereas in the $\mathrm{D}$ condition a significant inverse association appeared $(\mathrm{rs}(54)=-.406, p<.01)$, meaning that these participants clearly reverse the association among $\mathrm{RF}$ and $\mathrm{SpO}_{2}$. If we remind that both groups had significantly more $\mathrm{SpO}_{2}$ in the $\mathrm{D}$ condition than in the B condition (Table 2), we can suppose that for MMS participants a greater $\mathrm{RF}$ in $\mathrm{B}$ condition is a solution that their body resorts to ensure enough $\mathrm{SpO}_{2}$, naturally with a supplementary effort for their hearts, which can be advantageously substituted by the D technic, with a significant reduction of HR (Table 2). An additional proof of this abrupt physiological change in the MMS group is the absence of association of RF among conditions ( $\operatorname{rs}(54)$ $=.012, \mathrm{~ns})$, contrasting with the presence of significant direct association in the ONH group $(\operatorname{rs}(78)=.471, p<.0001)$.

Table 3: Descriptive statistics (Mean \pm Standard Deviation, Median), Wilcoxon test (W), effect size ( $\mathrm{r}$ ), and Wilcoxon rank-biserial correlation coefficient (rrb), for heart rate variability parameters for the sample ( $N=22)$, in baseline (B) and diaphragmatic breathing (D) conditions.

\begin{tabular}{|c|c|c|c|c|c|c|c|}
\hline HRV Parameters & B & D & GL & W & p & r & rrb \\
\hline HRVi & $7.44 \pm 3.35,6.76$ & $8.07 \pm 3.69,7.17$ & 22 & 1.964 & 0.05 & 0.42 & 0.36 \\
\hline HF & $107.00 \pm 195.40,47.60$ & $189.52285 .88,57.91$ & 22 & 2.549 & 0.01 & 0.54 & 0.44 \\
\hline LF & $144.59 \pm 198.07,61.46$ & $194.36 \pm 242.80,99.35$ & 22 & 1.964 & 0.05 & 0.42 & 0.44 \\
\hline
\end{tabular}

HRVI: Heart Rate Variability Index; HF: High Frequency 
Careful should be taken in the analysis of HRV parameters, because only with all participants and only in three parameters (HRVi, HF, LF) significant differences were found; additionally, because in the case of HF and LF its standard deviations are higher than the mean. However, the effect size and the Wilcoxon rankbiserial correlation coefficient are sufficiently high to allow some protected statistical analysis (Table 3).

Both HRV parameters significantly augmented from B condition to D condition (Table 3). Considering mean RF in D condition (Table 1), it would be expectable that both HF and LF became significantly higher (Song \& Lehrer, 2003). Correlations give us additional information. In B condition, the higher the HRVi the higher the $\mathrm{SpO}_{2}$ $(\mathrm{rs}(22)=.550, p<.01)$, the $\operatorname{LF}(\operatorname{rs}(22)=.738, p<.001)$ and the $\mathrm{HF}(\mathrm{rs}(22)=.704, p<.001)$, and the lower the DP $(\mathrm{rs}(22)=-.438$, $\mathrm{p}<.05$ ); reinforcing the hypothesis that only in participants with higher HRV have better oxygen supply and greater autonomous nervous activity. No association occurred with BF. In D condition, the higher the HRVi the higher the $\mathrm{SpO}_{2}(\mathrm{rs}(22)=.562, p<.01)$, the higher LF $(\operatorname{rs}(22)=.673, p<.001)$, and the HF $(\operatorname{rs}(22)=.565$, $p<.01)$; additionally, the higher the LF the higher the $\mathrm{SpO}_{2}(\mathrm{rs}(22)$ $=.848, p<.05)$, and the lower the BF the higher the $p(\mathrm{rs}(22)=$ - .541, $p<.01$ ). However, when we split the sample by blood pressure status, $\mathrm{SpO}_{2}$ improvement in $\mathrm{D}$ condition reveals positive significant association in MMS group (HRVi- rs(9) = .709, $p<.05$; LF- $\operatorname{rs}(9)=.895, p<.001$, HF- rs(9) = .734, $p<.05)$; but not in ONH group (HRVi- rs(13) = .268, ns; LF- rs(13) =.143, ns, HF- rs(13) = -.252 , ns), meaning that it was the group with problems with blood pressure that really beneficiated with probable contribution of $\mathrm{D}$ breathing technic in the autonomous nervous system contribution to enhancement of peripheral oxygen saturation.

\section{DISCUSSION}

A RF between 10 and 14 cycles per minute had beneficial (transient) effects in $\mathrm{BP}, \mathrm{HR}$, and $\mathrm{SpO}_{2}$ in these elderly [20-32]. D condition afforded these elderlies to a lower RF, associated with enhanced $\mathrm{SpO}_{2}$ [4], when in rest condition there were some cases of low saturation levels (78-85\%) [9-18]. With simple instructions, the elderly reduced their breathing frequency, heart rate, systolic pressure, and pulse pressure (systolic minus diastolic), and elevated their peripheral capillary oxygen saturation, even without reaching 6 respiratory cycles per minute.

The reduction of systolic pressure and of the pulse pressure is a stimulating result, because in elderly's hypertension with cardiovascular risk factor or associated clinical conditions, the pulse pressure showed a strong predictive value for cardiovascular events [1-10,13-5].

The results of this study showed that a respiratory training intervention, based on the acquisition of predominantly slow diaphragmatic breathing (as described above), brief and of lowcost, can be used to benefit cardiovascular functions in elderly [726,30-38]. The results of this study also support the hypothesis that a self-regulated paced breathing, predominantly diaphragmatic, can be used as a complementary non-pharmacological and non-clinical procedure for hypertension, probably, with additional advantage of bettering peripheral capillary oxygen saturation [4] and, higher baroreflex sensitivity, which is related inversely to arterial pressure [20-14-36]

\section{ACKNOWLEDGEMENT}

Funding information: This study has a grant from the
Portuguese Foundation for Science and Technology, I.P. (Number UIDP/04748/2020).

\section{REFERENCES}

1. Benetos A, Safar M, Rudnichi A, Smulyan H, Richard JL, et al. (1997) Pulse pressure: a predictor of long-term cardiovascular mortality in a French male population. Hypertension 30 : 1410-1415.

2. Bernardi L, Porta C, Spicuzza L, Bellwon J, Spadacini G, et al. (2002) Slow breathing increases arterial baroreflex sensitivity in patients with chronic heart failure. Circulation 105: 143-145. Bernardi L, Spadacini G, Bellwon J, Hajric R, Roskamm H, et al. (1998) Effect of breathing rate on oxygen saturation and exercise performance in chronic heart failure. The Lancet 351(9112): 1308-1311.

3. Blacher J, Staessen JA, Girerd X, Gasowski J, Thijs L, et al. (2000) Pulse pressure does not mean pressure determines cardiovascular risk in older hypertensive patients. Archives of International Medicine 160: 1085-1089.

4. Camm AJ (1996) Heart rate variability-Standards of measurement, physiological interpretation, and clinical use. Circulation 93: 1043-1065.

5. Cea JI, Caso R, Reyes Del Paso GA, Gonzalez Pinto A, Brazal J, et al. (2005) Blood pressure is reduced after a breathing intervention in mild hypertensive patients. Psychophysiology 34: S62.

6. Chobanian AV, Bakris, GL, Black HR, Cushman WC, Green LA, et al. (2003) The seventh report of the joint national committee on prevention, detection, evaluation, and treatment of high blood pressure: the JNC 7 report. Jama 289(19): 2560-2571.

7. Colodny N (2001) Effects of age, gender, disease and multisystem involvement on oxygen saturation levels in dysphagic persons. Dysphagia 16(1): 48-57.

8. Darne B, Girerd X, Safar M, Cambien F, Guize L (1989) Pulsatile versus steady component of blood pressure: a cross-sectional analysis and a prospective analysis on cardiovascular mortality. Hypertension 13: 392 400 .

9. Denot Ledunois S, Vardon G, Perruchet P, Gallego J (1998) Effects of voluntary changes in breathing frequency on respiratory comfort. Biological psychology 49(1): 71-82.

10. A (2013) Discovering statistics using IBM SPSS statistics. Sage.

11. Gasowski J, Fagard RH, Staessen JA, Grodzicki T, Pocock S, et al. (2002) INDANA Project Collaborators. Pulsatile blood pressure component as predictor of mortality in hypertension: a meta-analysis of clinical trial control groups. J of Hypertension 20: 145-151.

12. Gerritsen J, Voorde BJ, Dekker JM, Kostense PJ, Bouter LM, et al. (2000) Baroreflex sensitivity in the elderly: influence of age, breathing and spectral methods. Clin Sci 99(5): 371-381.

13. Giles D, Draper N, Neil W (2016) Validity of the Polar V800 heart rate monitor to measure RR intervals at rest. Eur J of Appl physiol 116(3) : 563-571.

14. Goso Y, Asanoi H, Ishise H, Kameyama T, Hirai T, et al. (2001) Respiratory modulation of muscle sympathetic nerve activity in patients with chronic heart failure. Circulation 104: 418-423.

15. Guzzetti S, Piccaluga E, Casati R, Cerutti S, Lombardi F, et al. (1988) Sympathetic predominance in essential hypertension: a study employing spectral analysis of heart rate variability. J of hypertens 6(9): 711-717.

16. Hirst LJ, Ford GA, Gibson GJ, Wilson JA (2002) Swallow-induced alterations in breathing in normal older people. Dysphagia 17(2): 152161.

17. Jonas BS, Franks P, Ingram DD (1996) Are symptoms of anxiety and depression risk factors for hypertension? longitudinal evidence from the National Health and Nutrition Examination Survey I Epidemiologic Follow-up Study. Arch of Fam med 6(1): 43-49.

18. Joseph CN, Porta C, Casucci G, Casiraghi N, Maffeis M, et al. (2005) Slow breathing improves arterial baroreflex sensitivity and decreases blood pressure in essential hypertension. Hypertension 46(4): 714-718. 
19. Laurent S, Cockcroft J, Van Bortel L, Boutouyrie P, Giannattasio C, et al. (2006) Expert consensus document on arterial stiffness: methodological issues and clinical applications. Eur heart J 27(21): 2588-2605.

20. Lehrer PM, Vaschillo E, Vaschillo B, Lu S, Eckberg DL, et al. (2003) Heart rate variability biofeedback increases baroreflex gain and peak expiratory flow. Psychosom Med 65: 796-805.

21. Mancia G, Fagard R, Narkiewicz K, Redon J, Zanchetti A, et al. (2013) $2013 \mathrm{ESH} / \mathrm{ESC}$ guidelines for the management of arterial hypertension: the task force for the management of arterial hypertension of the European society of hypertension (ESH) and of the European Society of Cardiology (ESC). Eur Heart J 34: 2159-219.

22. Mancia G, De Backer G, Dominiczak A, Cifkova R, Fagard R, et al. (2007) 2007 Guidelines for the management of arterial hypertension. European Heart Journal 28(12): 1462-1536.

23. Mancia G, Ferrari A, Gregorini L, Parati G, Pomidossi G,et al. (1983) Blood pressure and heart rate variabilities in normotensive and hypertensive human beings. Circulation research 53(1): 96-104.

24. Meles E, Giannattasio C, Failla M, Gentile G, Capra A, et al. (2004) Nonpharmacological treatment of hypertension by respiratory exercise in the home setting. American J of Hypertension 17: 370-374.

25. Mortara A, Bernardi L, Pinna G, Spadacini G, Maestri R, et al. (1996) Alterations of breathing in chronic heart failure: clinical relevance of arterial oxygen saturation instability. Clinical science (London, England: 1979) 91: $72-74$

26. Parati G, Omboni S, Frattola A, Di Rienzo M, Zanchetti A, et al. (1992) Dynamic evaluation of the baroreflex in ambulant subjects. In Di Rienzo M, Mancia G (Eds), Blood Pressure and Heart Rate Variability (pp. 123137). Amsterdam, Netherlands: IOS Press.

27. Parati G, Di Rienzo M, Bertinieri G, Pomidossi G, Casadei R, et al. (1988) Evaluation of the baroreceptor-heart rate reflex by 24-hour intra-arterial blood pressure monitoring in humans. Hypertension 12(2): 214-222.

28. Parati G, Izzo JL, Gavish B (2003) Respiration and blood pressure. In JL Izzo, HR Black (Eds.), Hypertension primer (chap. A40, pp. 117-120). Baltimore: Lippincott, Williams, and Wilkins.
29. Reyes Del Paso GA, Langewitz W, Robles H, Perez N (1996) A between-subjects comparison of respiratory sinus arrhythmia and baroreceptor cardiac reflex sensitivity as non-invasive measures of tonic parasympathetic cardiac control. Int J of Psychophysiol 22: 163-171.

30. Reys Del Paso GA, Cea JI, González Pinto A, Cabo OM, Caso R, et al. (2006) Short-term effects of a brief respiratory training on baroreceptor cardiac reflex function in normotensive and mild hypertensive subjects. Appl Psychophysiol and Biofeedback 31(1): 37-49.

31. Rodríguez Liñares L, Lado MJ, Vila XA, Mendez AJ, Cuesta P, et al. (2014) gHRV: Heart rate variability analysis made easy. Comput Methods and Programs in Biomed 116: 26-38.

32. Rodriguez Linares L, Vila XA, Mendez AJ (2012) gHRV: a user friendly application for HRV analysis. 7th Iberian Conference on Information Systems and Technologies (Cisti 2012).

33. Sinski M, Lewandowski J, Abramczyk P, Gaciong Z (2006) Why study sympathetic nervous system? Journal of Physiology and Pharmacology: An Official Journal of the Polish Physiological Society 57: 79-92.

34. Smyth HS, Sleight P, Pickering GW (1969) Reflex regulation of arterial pressure during sleep in man A quantitative method of assessing baroreflex sensitivity. Circulation research, 24(1): 109-121.

35. Song HS, Lehrer PM (2003) The effects of specific respiratory rates on heart rate and heart rate variability. Appl Psychophysiol and Biofeedback 28(1): 13-23.

36. Stark R, Schienle A, Walter B, Vaitl D (2000) Effects of paced respiration on heart period and heart period variability. Psychophysiology 37(3): 302-309.

37. Vila J, Palacios F, Presedo J (1997) Time-frequency analysis of heart-rate variability. IEEE Engineering in Medicine and Biology Magazine 16: 119126.

38. Viskoper R, Shapira I, Priluck R, Mindlin R, Chornia L, et al. (2003) Nonpharmacological treatment of resistant hypertensives by deviceguided slow breathing exercises. American Journal of Hypertension 16: 484-487. 